\title{
laborhifórico
}

ISSN 2359-6910

https://revistas.ufrj.br/index.php/lh/

ARTIGO

Recebido em 31 de maio de 2020

Aprovado em 21 de julho de 2020

\section{Léxico e História da Escravatura: reflexões críticas a partir de documentos históricos}

Lexicon and History of Slavery: critical reflections from historical documents

DOI: https://doi.org/10.24206/lh.v6i3.35125

Eliana Correia Brandão Gonçalves

Professora Adjunta da Área de Filologia Românica do Instituto de Letras da UFBA. Atua na Graduação e como Professora Permanente do Programa de Pós-Graduação em Língua e Cultura - PPGLinC-UFBA. Graduada em Letras, Mestre em Letras e Linguística - Crítica Textual - e Doutora em Letras e Linguística - Linguística Histórica - pela UFBA. Tem experiência na área de Filologia e Linguística, com ênfase em História da Língua e História das Transmissões Textuais e Edições de Documentos Históricos e Estudos Lexicais e Semânticos. Coordenadora do Grupo de Estudos Filológicos e Lexicais GEFILL-UFBA.

E-mail: elianabrand7@gmail.com

ORCID: https://orcid.org/0000-0003-1064-5382 


\title{
RESUMO
}

O artigo apresenta considerações sobre a articulação entre a análise do léxico e a história da escravatura no Brasil, a partir da edição de documentos históricos do século XVIII e XIX, vinculando-se a uma das frentes de pesquisa da Linguística Histórica. Assim, com base em textos de variados tipos documentais, foram selecionadas quatro unidades lexicais, vinculadas à esfera semântica da escravidão, a saber, escravatura, escravo, mulato e pelourinho, considerando a descrição e a análise das suas significações contextuais, lexicográficas e historiográficas, bem como as suas reverberações discursivas. Nesse viés, a pesquisa com o léxico nos remete a um lugar imaterial de fortes matizes históricas e políticas, que se fortalecem pelas memórias de resistências dos escravizados, atualizando e alimentando esse cenário e essas cenas de outras significações sócio-culturais, ideológicas e políticas.

Palavras-chave: Léxico. História da Escravatura. Violência. Resistência. Documentos do Arquivo Histórico Ultramarino.

\begin{abstract}
The article presents considerations on the articulation between the analysis of the lexicon and the history of slavery in Brazil, from the edition of historical documents from the 18th and 19th centuries, linking to one of the research fronts of Historical Linguistics. Thus, based on texts of various documentary types, four lexical units were selected, linked to the semantic sphere of slavery, namely, slavery, slave, mulatto and pillory, considering the description and analysis of their contextual, lexicographic and historiographic meanings, as well as its discursive reverberations. In this bias, research with the lexicon takes us to an immaterial place of strong historical and political nuances, which are strengthened by the memories of resistance of the enslaved, updating and feeding this scenario and these scenes of other socio-cultural, ideological and political meanings.
\end{abstract}

Keywords: Lexicon. History of Slavery. Violence. Resistance. Documents of the Overseas Historical Archive. 


\section{Palavras Iniciais}

$\mathrm{O}$ artigo apresenta reflexões sobre a articulação entre o estudo do léxico e a história da escravatura no Brasil, a partir de fontes históricas datadas dos séculos XVIII e XIX. A compilação de textos de diversos tipos documentais possibilita a reconstituição de corpora diacrônicos para a análise lexical e semântica de unidades lexicais que circularam nos usos linguísticos setecentista e oitocentista, revelando as histórias partilhadas entre Portugal e suas colônias. Nesse viés, a análise dos dados linguísticos do léxico resgata e reavalia as memórias de violências e resistências, por meio da seleção de alguns itens lexicais vinculados à esfera semântica da escravatura, considerando a descrição e a análise das suas significações contextuais, lexicográficas e historiográficas, bem como as suas reverberações discursivas.

Nesse caminho, para justificar a inserção de um documento no âmbito da história da escravatura no Brasil, adota-se a definição de documentos históricos como "todos aqueles relacionados à América Portuguesa, quer oriundos dela quer oriundos da sede do Império Português" (DIAS; BIVAR, 2005, p. 18). Esse recorte revela que a análise do léxico em documentos históricos estará articulada com as escolhas metodológicas adotadas pelo pesquisador, diante de seus objetivos, da pluralidade de espécies documentais e da difusão do testemunho nos contextos administrativos, socioculturais e políticos.

Em relação às normas de edição dos documentos, grande parte das edições voltadas à pesquisa linguística priorizam critérios filológicos de caráter mais conservador, diferentemente das edições voltados para o público não especializado e, portanto, formado de possíveis leitores não interessados nos fatos de língua. Para tanto, a organização de edições de documentos históricos para fins linguísticos requer do pesquisador conhecimentos linguísticos, diplomáticos, paleográficos e historiográficos, que tornam viáveis o processo de leitura crítica das fontes documentais manuscritas, a partir da interpretação dos usos sociais da escrita, dos caracteres gráficos da escrita da época, das abreviaturas constantes nos textos, dos arcaísmos e das mudanças semânticas que atingem o léxico da língua.

$\mathrm{Na}$ construção dessas relações entre fontes históricas escritas, sociedade e análise do léxico, o pesquisador pode mobilizar diferentes modos de leitura, de acordo com suas finalidades. Nesse sentido, os usos linguísticos e sociais da escrita estão vinculados ao conhecimento dos textos. Portanto, para a análise dos dados lexicais, recorreremos à documentação remanescente do passado (MATTOS E SILVA, 2008; MAIA, 2012; MARQUILHAS 2010), em particular aos documentos disponibilizados nos acervos da Biblioteca Nacional Digital do Rio de Janeiro e do Arquivo Histórico Ultramarino de Lisboa, com o fim de analisar a relação produtiva entre o estudo da organização semântica do léxico e a história da escravatura, em suas articulações com a violência. 
Portanto, para subsidiar as discussões, serão desenvolvidas observações e análises preliminares sobre a história da língua no contexto histórico-diacrônico, dando destaque à relevância da organização de documentos históricos e à análise de verbetes de dicionários do português para o desenvolvimento de estudos linguístico-filológicos de cunho lexical, ancorando nossa análise em aporte teórico da Filologia e da Linguística Histórica (MARQUILHAS, 2010; MAIA, 2012; MATTOS E SILVA, 2008; PONS RODRÍGUEZ, 2006; GONÇALVES, 2018, 2019), dos estudos do léxico (MURAKAWA, 2001, 2015; MURAKAWA; GONÇALVES, 2015; BIDERMAN, 2001; REY-DEBOVE, 1973; HAENSCH, 1982; SECO, 2003; COELHO, 2008; BARBOSA, 2001; GONÇALVES, 2017); e da Historiografia (REIS, 1992, 1996; TAVARES, 2001; NUNES, 2013; DANTAS, 2011).

Particularmente, o estudo do léxico apresenta rastros da história social e política da tortura e da desumanização imposta aos sujeitos escravizados, mas também dos seus movimentos de enfrentamento e de resistência. Nesse viés, essa pesquisa também reflete sobre a constituição de corpora para o desenvolvimento de análises lexicais, vinculando-se a uma das frentes de pesquisa da Linguística Histórica.

\section{Fontes Históricas e História da Língua: caminhos metodológicos para a eleição do corpus}

É a dimensão histórica e interpretativa que une linguistas e filólogos em torno dos documentos históricos, que apresentam variações no tempo e no espaço. O texto-documento é objeto sóciohistórico, material, cultural e político que registra os rastros das adoções lexicais dos sujeitos. Dessa forma, os registros escritos constituem-se como fontes relevantes para o conhecimento do léxico e seus usos sociais, em fases pretéritas da língua.

A história da língua é marcada por um processo complexo, envolvendo corpora textuais, que autorizam o reconhecimento de um dado linguístico, e alterações e rupturas semânticas de tradições e de usos linguísticos, a fim de apresentar uma análise fundada no sujeito, na linguagem, no discurso. Em particular, os documentos viabilizam esse conhecimento a partir de outros prismas linguísticos e historiográficos, pois "cada registro de um texto escrito constitui um testemunho" (CAMBRAIA, 2005, p. 63) dos usos linguísticos que figuraram nas narrativas históricas. Então por que não articular a análise desses registros lexicais às edições de fontes históricas e aos registros de dados historiográficos sobre o Brasil?

A questão da história da escravatura e suas interfaces com as memórias de violências e resistências são bastante recorrentes na documentação remanescente sobre a Bahia e o Brasil do século XVIII e 
XIX. Nossa base de dados textuais para a análise do léxico foi arquitetada a partir de documentos de acervos de instituições de guarda nacionais e estrangeiras, a exemplo da Biblioteca Nacional, depositária oficial de vários manuscritos referentes à história da escravatura no Brasil e na Bahia; e, precisamente nesse artigo, do Arquivo Histórico Ultramarino (AHU), em Lisboa, que guarda os documentos recebidos, produzidos, registrados e acumulados pelos órgãos da administração militar, judicial e eclesiástica do império colonial português e que foram catalogados pelo Projeto Resgate Barão do Rio Branco, em 2009 (BELLOTTO, 2006).

O antigo Conselho Histórico Ultramarino (1642 - 1833), criado por D. João IV, foi responsável pela produção de documentos que constituem a memória de cinco séculos da administração portuguesa sobre suas colônias. Esses condicionamentos sóciohistóricos, no período colonial, sinalizam para o fato de que toda a tramitação da documentação histórica, enviada das colônias para o rei, inicialmente passava pela leitura e análise do Conselho Ultramarino, a fim de ser remetida ao monarca, para deliberação (FACHIN, 2006, p. 9; ACIOLI, 1994, p. 58). A importância histórica dessa documentação luso-brasileira também é reiterada por Alencastro (2000, p. 10), quando afirma que o estudo histórico de nosso território "deve abranger toda a extensão da lusofonia, da documentação ultramarina onde estão registrados os contratos entre as culturas que nos formaram".

A análise do léxico vincula-se ao método de compilação das fontes documentais escritas disponíveis. Dessa forma, os corpora textuais permitem a seleção, a descrição e o exame do léxico temático, com o objetivo de compor glossários e vocabulários, mostrando diferentes compreensões linguísticas e discursivas sobre o componente lexical, que se apresenta dinâmico e mutante, conforme cada tipologia textual. Portanto, nesse contexto, ancorado no trabalho lexicográfico, é possível compilar as unidades lexicais, reatualizando a história da escravatura e socializando aos pesquisadores e ao público em geral dados linguísticos relevantes para o estudo das narrativas históricas, baianas e lusobrasileiras, registradas nesses documentos.

Nesse exercício de crítica filológica-linguística, a memória da escravatura sinaliza para a história social da Bahia e do Brasil e os fenômenos sócio-culturais e políticos que o definem, visto que, apesar de ser marcada pelas descontinuidades, independente das aparentes continuidades,

A história deve respeitar as exigências da memória, necessárias para curar as infinitas feridas, mas, ao mesmo tempo, ela deve reafirmar a especificidade do regime de conhecimento que lhe é próprio, o qual supõe o exercício da crítica, a confrontação entre as razões dos atores e as circunstâncias constrangedoras que eles ignoram, assim como a produção de um saber possibilitada por operações controladas por uma comunidade científica. É marcando sua diferença, (...) em relação a poderosos discursos, ficcionais ou memoriais, que, eles também, dão uma presença àquilo que já passou, que a história tem condição de assumir a própria responsabilidade: tornar inteligíveis as heranças acumuladas e as descontinuidades fundadoras que nos fizeram o que somos. (CHARTIER, 2010, p. 12-14) 
Nesse viés, descrever e analisar o léxico a partir de edições de documentação histórica do passado é uma das linhas de trabalho da Linguística Histórica. A pesquisa com a história da língua é uma atividade interpretativa, que mobiliza soluções diferenciadas, adotando critérios teóricometodológicos de acordo com a diversidade textual, a edição e o tipo de estudo lexical a ser desenvolvido. Pons Rodríguez (2006) traça coordenadas em defesa do complexo trabalho, desenvolvido pelos linguistas, com a história da língua e com o estudo dos diversos níveis e fenômenos linguísticos mostrados no texto:

Entre los condicionamentos particulares de la Historia de la Lengua como disciplina está el tipo de fuentes en que se basan los estúdios, la base de datos sobre la que se trabaja para extraer conclusiones. Todo estudioso de la historia de la lengua en cualquiera de sus planos está atado y asegurado em sus intepretaciones del decurso histórico por lo que dicen los textos, por las soluciones lingüísticas que sus productores escogieron y por las que desecharon. ${ }^{1}$ (PONS RODRÍGUEZ, 2006, p. 9)

$\mathrm{Na}$ análise das línguas, em suas sincronias pretéritas, observa-se que os falantes são impossibilitados de testemunhar (GONÇALVES, 2018, 2019) e, diante da ausência de dados diretos desses falantes de fases pretéritas da língua, os textos testemunham os rastros da história da língua, permitindo a explicação de processos históricos da mudança linguística. Desse modo, os textos "falam", pois eles registram parte dos usos linguísticos dos escreventes, nossos informantes pretéritos já desaparecidos.

Essa práxis linguístico-filológica é alicerçada em uma postura criteriosa e crítica, que percebe o texto como produto da cultura e da história da língua e dos falantes. Nesse sentido, a articulação entre a análise do léxico e a história da escravatura é realizada, no geral, fundamentando-se nos seguintes critérios:

(I) Mapeamento e seleção dos documentos históricos dos séculos XVIII e XIX, disponíveis em instituições de guarda, com base no recorte temático, escravatura e seus contextos de violência, e no recorte cronológico, posto que os documentos apresentam memórias e histórias partilhadas do vasto império colonial português e da organização do cotidiano de suas colônias;

(II) Leitura e análise da edição fac-similar, semidiplomática e, em alguns casos, da edição interpretativa de diversos tipos documentais, entre os quais Ofícios,

\footnotetext{
${ }^{1}$ Tradução livre: Entre as condições particulares da História da Língua como disciplina está o tipo de fontes nas quais os estudos se baseiam, o banco de dados no qual se trabalha para tirar conclusões. Todo estudioso da história da língua em qualquer um de seus planos está limitado e seguro em suas interpretações do curso histórico pelo que dizem os textos, pelas soluções linguísticas que seus produtores escolheram e pelas quais descartaram.
} 
Cartas, Provisões, Requerimentos, Resoluções, Pareceres, Consultas, Regimentos e Alvarás, uma vez que esses documentos regulavam ou tinham a pretensão de regular/monopolizar o cotidiano da colônia (BELLOTTO, 2002) e também apresentam um repertório linguístico diversificado;

(III) Análise linguístico-filológica ancorada em produtos editoriais, que preservam as marcas linguísticas do texto, com o fim de proceder à seleção, descrição e exame do léxico temático, em particular das unidades lexicais, com base em dicionários e na discussão científica produzida pelos historiadores.

Por fim, seguindo-se esses critérios, percebe-se que a história do léxico é embasada na constituição de edições de documentos, na consulta às obras lexicográficas e na adoção de dados da historiografia. Essa articulação pode ser visualizada na figura a seguir:

Figura 1 - A história do léxico e a construção de trilhas linguísticas.

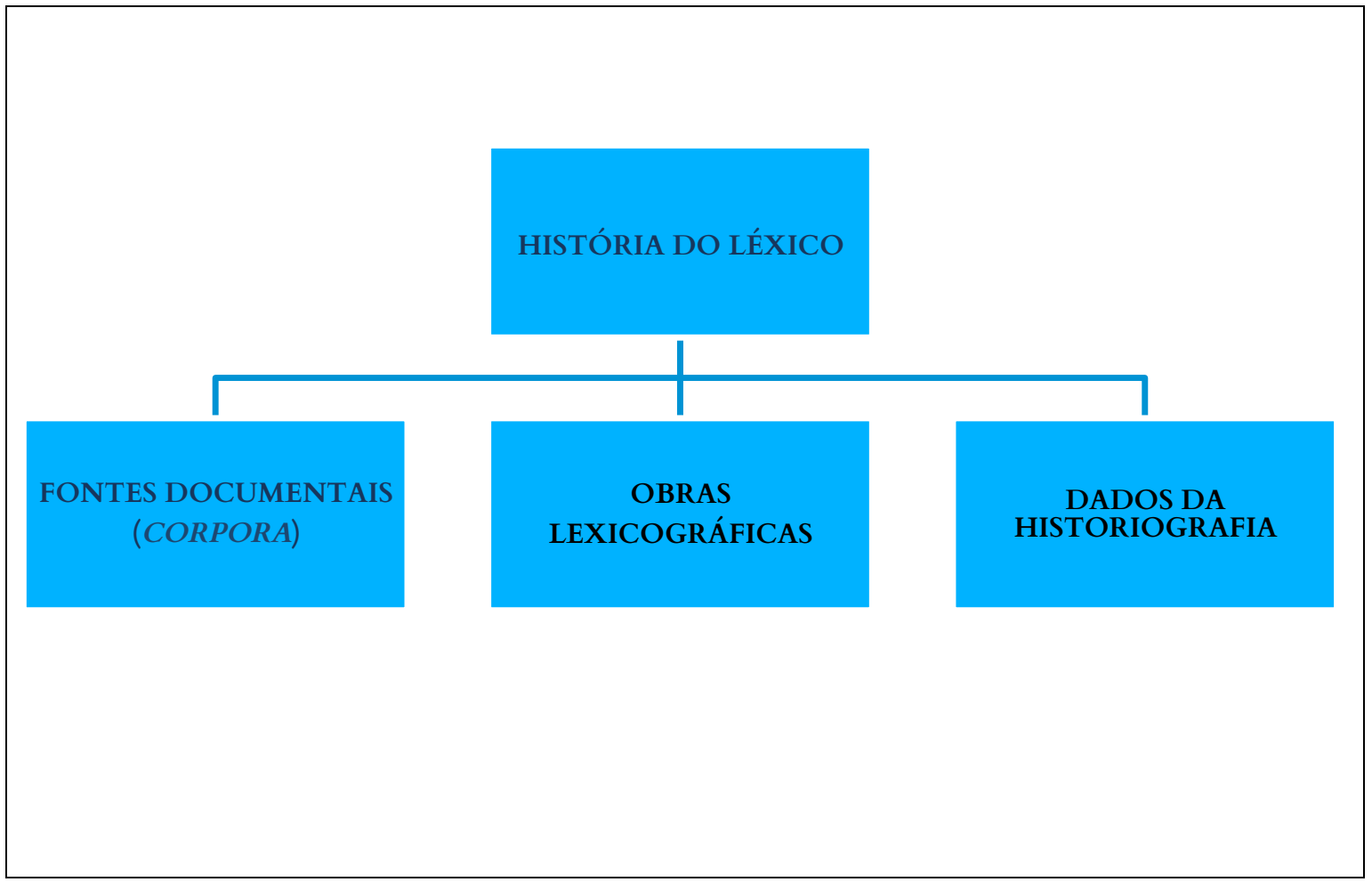

Fonte: Elaborado pela própria autora.

Como se pode notar, essa interpretação opera entre a objetividade e a subjetividade, entre a distância e a proximidade, pois também são análises articuladas aos interrogantes do nosso tempo em relação aos outros tempos. Nesse caminho, de descontinuidades das narrativas históricas e dos usos linguísticos, analisar criticamente o léxico é nos reportarmos a um passado em que não estivemos, esquadrinhando os rastros linguísticos, pois essa é a opção que nos restou, examinarmos os restos, os 
vestígios da memória linguística fraturada, que o passado e o tempo perpetuaram, e que só encontram visibilidade nas leituras de sincronias futuras.

\section{Língua, História e a Questão da Escravatura}

Os diálogos entre Lexicografia e Historiografia mobilizam o encontro da história da língua com a história dos escravizados no Brasil, além de mediar a descrição, a análise e a interpretação dos significados do repertório lexical que institucionalizam e legalizam historicamente a escravatura, evidenciando a reavaliação dos rastros político-sociais da colonização e seus desdobramentos.

O aporte teórico-metodológico, que subsidia a construção das análises das informações lexicográficas constantes nos verbetes dos dicionários, teve por base as propostas de lexicógrafos como Haensch et al. (1982); Seco (2003); Coelho (2008); Murakawa (2001, 2015); Murakawa; Gonçalves (2015); Biderman (2001); Rey-Debove (1973); e Barbosa (2001).

Coelho (2008, p. 14) afirma que o acervo lexical é formado por um "inventário das unidades significativas responsáveis pela conceituação e representação do universo empírico natural e sociocultural produzido pela atividade dos homens em sociedade". Desse modo, para fins de amostragem e para análise linguística e histórica, foram selecionadas quatro unidades lexicais, escravatura, escravo, mulato e pelourinho. Essa seleção foi norteada por uma coesão temática, previamente estabelecida pelo campo semântico relativo à escravidão.

Para tanto, são apresentadas sistematicamente reflexões, a partir da análise das definições apresentadas pelos dicionários de língua, acrescidas das considerações e discussões desenvolvidas pela historiografia. Essa ação metodológica permite a reconstrução e reformulação do universo de significações, além de viabilizar a seleção e a montagem da memória social da escravidão e da resistência.

Nesse caminho da construção da pesquisa, os dicionários são meios importantes para o estudo da história do léxico, visto que tanto a análise lexicográfica quanto a análise lexicológica apresentam um comprometimento histórico e estão fundamentadas em uma "documentación cronológica mínimamente fidedigna como una de sus bases imprescindibles $(. . .)^{2}$ (SECO, 2003).”

Os dicionários repertoriam parte das unidades lexicais que foram utilizadas na língua e buscam registrar e definir os signos lexicais referentes aos conceitos elaborados e cristalizados na cultura, traduzindo-se também como objeto de apropriação histórica e cultural por parte do consulente. As

${ }^{2}$ Tradução livre: "documentação cronológica minimamente fidedigna como uma de suas bases imprescindíveis (...)”. 
produções de sentidos não estão fossilizadas nos dicionários, mas os mesmos podem servir de referência discursiva, por registrar parte dos usos linguísticos e das acepções linguísticas que circularam e circulam nos contextos discursivo-sociais do passado e do presente.

$\mathrm{Na}$ análise das unidades lexicais, foram adotadas inicialmente três obras lexicográficas do português: Bluteau (1712-1718); Vieira (1871-1874); e Moraes Silva (1813). Em particular, a opção por essa tríade de dicionários justifica-se por aspectos que são defendidos por Murakawa (2001), em relação à composição do repertório lexical constante nesses produtos lexicográficos, entre os quais:

- Repertoriação de um corpus lexical autorizado de unidades lexicais que figuram entre as fases mais antigas da língua;

- Fundamentação em certo enciclopedismo, com descrições extensas e detalhadas, pretendendo oferecer o máximo de informação possível ao leitor;

- Apresentação e ampliação de outros termos definidores;

- Exposição de algumas unidades lexicais que não figuram mais nos dicionários atuais;

- Apresentação de exemplos abonados, extraídos de textos históricos e literários, como é o caso, em especial, do Bluteau.

Em particular, os produtos lexicográficos históricos, a exemplo dos dicionários históricos (MURAKAWA, 2001, 2015; GONÇALVES; MURAKAWA, 2015), podem registrar e descrever unidades lexicais de vários estágios reais de língua, com as suas várias acepções históricas vinculadas às fontes documentais. Nesse viés, para Barbosa (2001, p. 35), o dicionário elenca "[...] o universo dos lexemas, apresentando, para cada um deles, os vocábulos que representam suas diferentes acepções”, diferentemente dos vocabulários especializados que se organizam "ao nível de uma norma linguística e sociocultural, e têm como unidade-padrão o vocábulo, constituindo-se como conjuntos vocabulares, representativos de universos de discurso".

\section{Análise Lexical e a Trama Textual}

A história da escravatura no Brasil é marcada por atos de violência física, estrutural e institucional e ações preventivas, punitivas e repressivas, por parte das autoridades e milícias locais, contra a resistência negra, gerando, em contrapartida protestos coletivos comuns na história dos grupos 
subalternizados, entre os quais os enfrentamentos, as revoltas e os motins (GONÇALVES, 2018; REIS, 1992, 1996; DANTAS, 2011).

A violência em contextos de escravatura está tatuada na tela de diversas fontes textuais. Essas narrativas históricas reverberam ações de opressão, tortura e enforcamento, retratando a legitimação da imposição do sofrimento físico e emocional com justificativa de que o corpo-moeda de troca dos escravizados deve ser violentado, subalternizado, desumanizado.

Esses atos de violência contra os escravizados são delineados a partir da construção da arquitetura textual e vocabular, que nos remete à adoção de unidades lexicais relacionadas ao campo semântico da escravatura. Essas opções lexicais dos escreventes remetem historicamente à esfera da violência resultante das condições sociais e políticas a que eram submetidos os escravizados vindos da África ou nascidos no Brasil. São recorrentes os registros de práticas de punição adotadas cotidianamente, no período escravista, por meio de castigos publicizados ou torturas dos encarcerados, com o fim de intimidação física e cerceamento das vozes e dos movimentos contestatórios e de resistência negra, no contexto da escravatura.

Do ponto de vista político-econômico, a unidade lexical escravatura podia ser interpretada como um sintoma da ação colonizadora, pois era pela violência e pela desumanização, decorrentes da escravatura, que o Estado ficava mais forte e mais rico, como pode visualizado na edição semidiplomática de vários tipos documentais, entre os quais Ofícios, Cartas e Provisões, nos 19.610 (dezenove mil seiscentos e dez) documentos sobre a Bahia, catalogados pelo Projeto Resgate e provenientes do antigo Conselho Ultramarino. A edição semidiplomática é um "produto editorial que conserva as características linguísticas do texto, como a ortografia e a pontuação, além de sua constituição gramatical e lexical, desdobrando as abreviaturas” do texto (GONÇALVES, 2018, p. 160).

Em particular, nos séculos XVIII e XIX, os Ofícios eram bastante utilizados na América Portuguesa para comunicação interinstitucional no âmbito da Administração Pública, a fim de notificar atos e decisões administrativas, burocráticas, técnicas e políticas das autoridades. A composição de um Ofício, no âmbito do Conselho Ultramarino, demandava do escrevente o conhecimento de registros enunciativos, visto que o Ofício tinha em seu teor um perfil exclusivamente institucional e, portanto, estava vinculado aos assuntos de caráter oficial e normativo.

O excerto de um Ofício datado de 1755 registra a unidade lexical escravatura: "Cogitando eu há muito tempo o modo, e meyo mais adequado, effectivol para seenriquecer, e aumentar mais este Estado, povoandose a mayor partel do Continente delle, que está inculto, e não penetrado, por falta do poderl de gente, e escravatura [grifo nosso], [...].” (Ofício, 06 de julho de 1755, f. 1 r, L. 1 - 4 - AHU - ACL - CU - 005, Cx. 125, D. 9767 - Biblioteca Nacional ). 
Inicialmente, observa-se que o dicionário de Bluteau (1712-1718) não registra o verbete "Escravatura". Por outro lado, Moraes Silva (1813, v. 1, p. 743) registra a unidade lexical escravatura como substantivo feminino, mas com remissiva para que o consulente veja a unidade lexical escravaria. $\mathrm{Na}$ análise do verbete "Escravaria", o consulente encontra uma definição indicativa de classe gramatical da palavra-entrada, substantivo feminino coletivo, e que remete à definição de multidão de escravos, informação que pode deixar o consulente confuso, sem elucidação das suas dúvidas contextuais.

No entanto, uma análise mais pormenorizada da unidade lexical escravatura, a partir de fontes históricas do século XVIII e XIX, revela os condicionamentos sócio-históricos que ampliam as significações do item lexical, além de mostrar que, nesse período, a escravatura era um negócio, um dos meios considerados mais adequados para o crescimento do Brasil.

A história da violência e da tortura decorrentes das práticas abusivas senhoriais ainda é reiterada pela atividade lucrativa do tráfico de escravos e pelo trabalho escravo, que possibilitou o crescimento urbano da Bahia, com suas construções familiares e eclesiásticas. Desse modo, remetemos também à unidade lexical escravo, a partir das definições registradas nas tradições lexicográficas dos dicionários de Bluteau (1712-1728) e Moraes Silva (1813, v. 1, p. 743). Nesse contexto, o dicionário de Bluteau (1712-1728, v. 3, p. 224-225) registra a definição da unidade lexical escravo como "Aquelle, que naceo cativo, ou foi vendido, \& está debaixo do poder de Senhor”. A referida obra lexicográfica também apresenta dados etimológicos, remetendo escravo ao "Latim barbaro sclavus do qual fizeraõ os Italianos Schiavo". Dessa forma, escravo seria aquele que não possui liberdade, por ter sido vendido ou ter nascido cativo, estando em sujeição ao seu senhor.

Há vários relatos nos documentos históricos que reiteram essa acepção, que relaciona escravo ao indivíduo submetido à servidão e aos maus tratos a custo de violência física e institucional, principalmente em Cartas produzidas no âmbito do Conselho Ultramarino. Essas Cartas tinham variadas finalidades e intenções que motivaram a sua composição, apresentando subespécies em relação ao seu tipo documental. Para Bellotto (2002, p. 52), na administração colonial, a Carta era uma "correspondência enviada por autoridade subalterna/delegada ou súdito ao Rei” ou a outra autoridade. Portanto, desde que não se constituísse em um pedido, qualquer assunto de "caráter oficial ou particular que se desejasse expor" era comunicado por Cartas.

A Carta a seguir, datada de 1811, foi produzida por sujeito do alto escalão para autoridade pública para atualizá-la dos acontecimentos ocorridos na colônia, sem apresentar decisões formais e oficiais. Estas relações podem partir de uma escala hierárquica mais inferior para outra mais elevada ou vice-versa, ou ainda tramitar, em um mesmo âmbito, entre particulares, retratando e comprovando procedimentos administrativos e jurídicos. 
A propósito, essa definição de escravo está vinculada ao contexto da Carta (1811) de Felisberto Caldeira Brant Pontes ao [secretário de estado da Marinha e Ultramar] conde das Galveias [D. João de Almeida Melo e Castro] sobre o tratamento a ter com os escravos ${ }^{3}$ :

omulato Martinho, este disgrassadol que naó soube avaliar afortuna de servirl $\mathrm{aVossaExcelência.} \mathrm{Desde} \mathrm{que} \mathrm{VossaExcelência} \mathrm{me} \mathrm{encarre-I} \mathrm{gou} \mathrm{de} \mathrm{semelhante} \mathrm{commissaó}$ representei al VossaExcelência adeficuldade que encontrava, porquel os milhores escravos [grifo nosso] sem pancada fi-I caõ perdidos. [...] ${ }^{4}$ (Carta, 14 de fevereiro de 1811, f. 1v, l. 29 - AHU - ACL - CU - 005, Cx. 254, D. 17528 - Biblioteca Nacional). ${ }^{5}$

Seguindo a análise lexicográfica, o dicionário de Moraes Silva (1813, p. 743), além de apresentar a indicação da classe gramatical, substantivo masculino, define escravo como "Cativo, que está sem liberdade, no estado de servidão." Essa definição pode trazer problemas interpretativos para o consulente, levando-o talvez a tomar cativo como sinônimo de escravo, em todos os contextos. Nesse caso, os dicionários isoladamente não dão conta das definições e discussões específicas, em um recorte cronológico, histórico e espacial, a exemplo da questão da escravização na América Portuguesa.

Dessa forma, sinaliza-se que a definição de escravo apresenta o sema ' 'cativo', mas que nem todo cativo é um escravo. A unidade lexical cativo vincula-se mais ao indivíduo feito prisioneiro de guerra por um captor ou traficante. A condição de cativo pode ser transitória e/ ou acidental. Nesse viés, os povos vindos da África não podem ser considerados apenas cativos dos colonizadores portugueses. A historiografia brasileira e, em particular, a história baiana registram diversas narrativas de cativos como prisioneiros de guerra, casos de sequestros de cativos orquestrados por piratas e corsários e contextos de cativos indígenas. Precisamente, é o sema 'privado de liberdade', que marca tanto a unidade lexical cativo quanto a unidade lexical escravo.

Particularmente, na colonização portuguesa no Brasil e seus processos de escravização, a história da unidade lexical escravo remete também à legalização, ao "estado jurídico de reificação permanente do indivíduo adquirido para uso do seu proprietário (ALENCASTRO, 2000, p. 88). Escravo pode se referir tanto aos povos vindos da África ou nascidos no contexto de escravidão no Brasil, quanto aos índios, os chamados escravos da terra. Nesses dois contextos de extrema violência, no entanto escravo terá matizes diferentes, pois se tratam de configurações distintas de escravização. No caso, os

\footnotetext{
${ }^{3}$ Dado obtido por Tamires Sales de Quadros - Bolsista IC - CNPq - UFBA, sob a minha orientação, durante o período de 2017-2018 e 2018-2019.

${ }^{4}$ Seguindo os critérios da edição semidiplomática, as abreviaturas constantes no texto da Carta (1811) foram desenvolvidas e indicadas na unidade lexical com grifo itálico e foram conservadas as fronteiras das palavras, de acordo com o manuscrito.

${ }^{5}$ Cf. Biblioteca Nacional. https://bndigital.bn.gov.br/

${ }^{6}$ Usado no âmbito da Semântica Lexical, o sema é o traço de afinidade que se usa, intuitivamente, para estabelecer os campos semânticos e, portanto, definir os traços linguísticos que marcam ou diferenciam cada unidade lexical.
} 
escravizados vindos da África e nascidos no Brasil eram tratados como espólio herdado de conquistas e sua energia vital era usada como moeda de troca a ser negociada, comercializada e legitimada. No entanto, para Alencastro (2000):

Nenhum documento régio concebe os índios como energia humana em estado bruto, fator de produção e mercadoria pronta para ser vendida, marcada a ferro, comprada, embarcada herdada e - sobretudo - tributada pela coroa donde irrecusavelmente legalizada no seu estatuto reificado. [...] Patenteia-se a maneira contrastada pela qual os textos legais sobre o cativeiro [...] evoluem na América e na África Portuguesa. Não obstante as reviravoltas, uma sequência de diretivas régias editadas ao longo de três séculos - constituindo-se o mais denso corpo normativo lusitano referente a uma única matéria colonial - busca coibir a escravização dos índios. Na África, ao contrário, diminuem-se as dúvidas sobre a legitimidade da posse de escravos à medida que o comércio negreiro passa a ser objeto de estímulo por parte da Metrópole e do grande capital mercantil mobilizado pelos Asientos luso-espanhóis. (ALENCASTRO, 2000, p. $87-88 ; 120-121)$

Ainda a partir da leitura do excerto da Carta de 1811, destaca-se a relevância da análise da definição da unidade lexical mulato, no contexto "omulato Martinho, este disgrassadol que naó soube avaliar afortuna de servirl aVossaExcelência.[...]”. (Carta, 14 de fevereiro de 1811, f. 1v, 1. 29 - AHU ACL - CU - 005, Cx. 254, D. 17528 - Biblioteca Nacional).

O dicionário de Bluteau (1712-1718) registra as seguintes definições nos verbete Mulato e Mulata:

MULÂTO. Homem. Vid. Mulata.

Mulato. Besta. O macho asneiro, filho de cavallo, \& burra".

MULÂTA, \& Mulato. Filha, \& filho de branca, \& negra, ou de negro, \& de mulher branca. Este nome Mulato vem de Mú, ou mulo, animal gèrado de dous outros de differente especie." (BLUTEAU, 1712-1718, v.5, p. 4196)

Essa definição pejorativa é parcialmente reiterada pelo dicionário de Moraes Silva (1813, v. 2, p. 1137), que, além de apresentar a indicação da classe gramatical, substantivo masculino, registra o seu equivalente feminino, Mulata, recuperando em parte a definição registrada no Bluteau (1712-1718), ao afirmar que mulato é "filho, ou filha de preto com branca, ou ás avessas, ou de mulato com branca até certo gráo. S. O filho do cavallo, e burra.” O dicionário de Vieira (1871-1874) segue a mesma linha de definição, acrescentando apenas um ressalva para o fato de ser um "termo antiquado", mas sem dar mais informações sobre a questão. Assim, temos: 
MULATO, A, s. Termo antiquado. Macho asneiro, filho de cavallo e burra. (...)

- Figurada e popularmente: $\mathrm{O}$ branco com a negra, ou vice-versa, produzem um mulato cuja côr é morena, isto é, mixta de preta e branca; este mulato com uma branca produz um segundo mulato menos moreno que o primeiro; e se este segundo mulato se unir do mesmo modo a um indivíduo de raça branca, o terceiro mulato não terá mais do que uma côr morena ligeira, que desapparecerá inteiramente nas gerações immediatas. (VIEIRA, 1871-1874, v. 4, p. 351)

A análise das definições apresentadas pelos dicionários de Bluteau (1712-1718), e Moraes Silva (1813) e Vieira (1871-1874) leva o consulente a perceber que o processo definicional das unidades lexicais, especializadas ou não, é um processo polissêmico e variável e que recorre a vários métodos e combinações explicativas, de acordo com as fontes textuais e seus contextos cronológicos, sociais, históricos e políticos.

No contexto pós-colonial, ressalta-se o papel ativo do filólogo-linguista que mais do que ser um mediador de definições fixas, no estudo lexicográfico de documentos históricos, tem um comprometimento ético e político com a língua e, consequentemente, com a análise das produções, transformações e reatualizações das definições lexicográficas. Portanto, em tempos de defesa e combate ao racismo estrutural nas instituições, entre as quais a língua, atualmente é recomendável abolir do nosso uso linguístico as unidades lexicais de matizes racistas como mulato e mulata, visto que as mesmas remetem a um vocabulário histórico de opressão aos escravizados e a um discurso racista associado à história da escravidão no Brasil.

Em defesa da igualdade social, o nosso vocabulário precisa ter um comprometimento ético e humano, excluindo as matizes dos discursos racistas e preconceituosos que permeiam nossas escolhas lexicais. Logo, em meio às mudanças sociais e culturais e em defesa da igualdade social, os movimentos negros no Brasil reivindicam uma posição antirracista no uso da língua e, portanto, não é mais admissível a manutenção de unidades lexicais históricas que perpetuam as memórias de violências e que fortalecem a manutenção das desigualdades e a segregação do nosso povo negro no Brasil.

Por outro lado, seguindo ainda as trilhas dos textos históricos e a questão da escravatura, nessas telas há várias unidades lexicais referentes aos lugares de castigo, de revolta e até de pena de morte dos escravizados, por meio de enforcamentos. A unidade lexical pelourinho é demasiadamente conhecida e bastante recorrente nessas narrativas. O dicionário de Bluteau (1712-1728, v. 6, p. 383) registra pelourinho como "huma especie de columna, em algũ lugar publico da Cidade, ou Villa, em final da jurisdição, que tem de exercitar justiça com pena de morte.” A referida obra lexicográfica também apresenta dados etimológicos remetendo pelourinho ao francês pilori que por sua vez, vinculadas às tradições de punição romana, deriva do latim pilorium ou spilorium, salientando que antigamente no latim baixo a referida unidade lexical valia o mesmo que final de justiça com pena capital. $\mathrm{O}$ lexicógrafo ainda remete pellourinho a pellouro pequeno e faz referência a sua materialidade metálica. 
O dicionário de Moraes Silva (1813) reitera essa definição, indicando inclusive pellourinho como diminutivo de pellouro, porém ampliando aspectos descritos da sua materialidade. Nesse contexto, o substantivo masculino pellourinho é descrito como "columna de pedra, picota posta em alguma Praça de Vila, ou Cidade, á qual se ata pela cintura o preso, que se expõe á vergonha, ou é açoitado; tem argolas, onde se póde enforcar, e dar tratos de polé; e ponta de ferro de pôr cabeças; nele se affixão editos." (SILVA, 1813, v. 2, p. 424)

Por outro lado, a descrição do verbete apresentada no dicionário de Vieira (1871-1874) vinculase mais aos registros descritivos apresentados no dicionário de Moraes Silva (1813):

PELLOURINHO, s. m. Columna de pedra collocada em lugar publico, de cidade, villa, etc., tendo no cimo ganchos ou pontas, onde se espetam as cabeças dos criminosos, ou onde se atam os criminosos, para serem expostos á vergonha ou para serem açoutados; teem também argolas, onde se póde enforcar, e dar tratos de polé; também se acostumava affixar editos. [...] Diminutivo de Pellouro. (VIEIRA, 1871-1874, v. 4, p. 731)

A partir da análise dessas três obras lexicográficas, na definição da unidade lexical pelourinho, observa-se a:

(1) Indicação, nos três dicionários, do suporte físico utilizado para as ações de violência contra os corpos escravizados, "coluna”, e, em particular, nos dicionários de Vieira (1871-1874) e de Moraes Silva (1813), também são especificados o material do suporte, "de pedra”;

(2) Demarcação do espaço utilizado para exposição dos atos de violência, "lugar público" (BLUTEAU, 1712-1728; MORAES SILVA, 1813), na "cidade" ou "vila" (BLUTEAU, 1712-1728; VIEIRA, 1871-1874) e na "praça da vila" (MORAES SILVA, 1813);

(3) Exposição do sujeito para o qual é voltada a punição, "criminoso" (VIEIRA, 1871-1874) ou "preso" (MORAES SILVA, 1813);

(4) Eleição do instrumento utilizado para o castigo ou golpe aplicado durante a punição, "açoite";

(5) Sinalização das possíveis consequências jurídicas e punição dos crimes cometidos, "pena de morte" (BLUTEAU, 1712-1728), por meio do ato de "enforcar" (VIEIRA, 1871-1874; MORAES SILVA, 1813); 
(6) Divulgação pública da punição por parte das autoridades institucionais, por meio de editais afixados em locais públicos, "éditos" (VIEIRA, 1871-1874; MORAES SILVA, 1813).

Observadas as questões conceituais e históricas implicadas nas definições lexicográficas apresentadas nos verbetes dos dicionários de Bluteau (1712-1728), Moraes Silva (1813) e Vieira (18711874), passamos para a análise da unidade lexical pelourinho no contexto dos documentos históricos sobre a escravatura. A menção a essa unidade lexical é registrada na Provisão de 1756 do rei [D. José], que ordena a todos os governadores do Estado do Brasil das Relações da Bahia e do Rio de Janeiro que cumpra a ordem de cem açoites no pelourinho a todos os pretos e mulatos que andarem com facas salvo aqueles que forem livres. Para Bellotto (2002, p. 82), a Provisão é um documento utilizado por uma autoridade da administração colonial, no qual se registra um "ato pelo qual o rei confere algum benefício ou cargo a alguém ou emite ordem baseada em dispositivos anteriores", podendo "ser emitida também por tribunais superiores”, no exercício de suas atribuições.

A Provisão de 1756 estabelece a seguinte imposição legislativa:

[..] os pretos e mulatos escravos do Estado do Brazill que usarem de facas e mais armas prohibidas pelas Leys devinte enove de Marsol demil seis centos e dezanove el vinte esinco de Junho demil sete centos quarental e nove em lugar dapena dedez annos de galés impostos nas ditas Leys incorraõ os=I mesmos pretos emulatos escravos que as transgredirem na pena decem acoutesl dados no Pelourinho [grifo nosso] e repetidos por des dias alternados, oque senaõ estenderá com $=\mathrm{I}$ os negros e mulatos livres [...]. (Provisão - Cópia - 24 de janeiro de 1756, f. 1v, 1. 2-7. AHU - ACL - CU - 005, Cx. 127, D. 9881) ${ }^{7}$

O item lexical pelourinho circulou em vários textos históricos sobre a escravatura nos séculos XVIII e XIX. A análise do excerto da Provisão (1756) também reitera a definição da unidade lexical pelourinho como instrumento e lugar público de castigo. No entanto, nessa análise da história da palavra, a definição dessa unidade lexical, inicialmente recuperada pelos dicionários, ganha novas significações contextuais, a partir dos dados da historiografia.

Particularmente, a historiografia brasileira reitera a figura do pelourinho, no contexto da escravatura, como instrumento-lugar de violência, horror e tortura, no qual eram castigados, não necessariamente e somente sujeitos criminosos, mas os sujeitos escravizados. No contexto da colonização portuguesa, o pelourinho era usado para punir, através de açoites, castigos e enforcamentos. Essa coluna de pedra poderia ser instalada em vários lugares públicos da cidade, fato 
que justifica a locomoção e a instalação da coluna de pedra em diversos topos da Bahia, entre os séculos XVI a XIX.

A historiografia baiana registra que a coluna de pedra transitou em vários espaços em Salvador, entre os quais: a antiga Praça Municipal, atualmente conhecida como Praça Tomé de Souza; o Terreiro de Jesus; pelo largo das Portas de São Bento, nas proximidades da Praça Castro Alves; e também no largo das Portas do Carmo, onde se situa atualmente o bairro denominado Pelourinho (REIS, 1992, 1996; TAVARES, 2001; NUNES, 2013).

Por fim, a unidade lexical pelourinho poderia estar associada apenas à rememoração na qual se esconde a violência no contexto da escravatura, assinalando um instrumento-lugar, no qual se divulgou publicamente as estratégias punitivas, por parte das autoridades institucionais. Mas a unidade lexical pelourinho também pode ser interpretada como locus que guarda historicamente os vestígios materiais e imateriais da escravidão na Bahia. Na contemporaneidade, a história dessa palavra nos remete a um lugar imaterial de fortes matizes históricas e políticas, que se fortalecem pelas memórias de resistências dos escravizados, atualizando e alimentando esse cenário e essas cenas de outras significações. Essas novas significações reverberam nesse sair do povo negro do lugar de subalternidade, ocupando lugares sócio-culturais e ideológicos, nas discussões e ações que se instituem nas nossas agendas políticas, colocando em pauta a questão histórica do racismo, da desigualdade social, da consciência e da resistência negra e do repúdio à violência em todos os seus âmbitos, étnicoracial, estrutural, institucional e simbólico.

\section{Considerações Finais}

Esse estudo revela a diversidade textual e linguística dos corpora históricos, além de apresentar contribuições para a análise histórico-diacrônica do léxico, a partir do estudo lexicográfico e historiográfico das unidades lexicais relacionadas aos contextos de escravidão. Assim, as breves considerações aqui apresentadas interrogam a vinculação entre lexicografia e história da escravatura, considerando o registro dessas unidades lexicais em textos históricos de diversas tipologias textuais e comparando as definições apresentadas pelas obras lexicográficas mais antigas com as considerações interpretativas e elucidativas da historiografia.

Desse modo, o estudo das unidades lexicais disponibiliza aos pesquisadores e ao público em geral análises sobre a relação entre o léxico e as narrativas históricas luso-brasileiras, que tematizam a história da escravatura na América e na África Portuguesa em seus recorrentes e diversificados contextos de violência física, simbólica e estrutural. Consequentemente, a análise da história do léxico manifesta-se 
como um gesto crítico e político, uma ação necessária de resistência, diante de temas complexos que ocupam a nossa agenda social e política na contemporaneidade.

Para tanto, a utilização dos corpora textuais viabiliza a abonação das unidades lexicais historicamente registradas, vinculando-as às questões sociais, políticas e jurídicas. Nesse viés, a pesquisa lexical passa a se constituir como espaço ideológico, por meio da reflexão e da análise das ampliações e reatualizações semânticas, que são incorporadas às unidades lexicais, reafirmando a relevância da análise do léxico e considerando as condições de produção dos textos, os contextos históricos dos usos lexicais e os vestígios das memórias e das histórias, em nosso caso, de violências e resistências em contextos de escravatura. 


\section{Referências bibliográficas}

ACIOLI, Vera Lúcia Costa. A escrita no Brasil colônia: um guia para leitura de documentos manuscritos. Recife: EDUFPE/ FUNDAJ/ Massangana, 1994.

ALENCASTRO, Luiz Felipe. O trato dos viventes: formação do Brasil no Atlântico Sul. São Paulo: Companhia das Letras, 2000.

BARBOSA, Maria Aparecida. Dicionário, vocabulário, glossário: concepções. In: ALVES, Ieda Maria. (Org.). A constituição da normalização terminológica no Brasil. 2 ed. São Paulo: FFLCH/CITRAT, 2001. p. 23-45.

BELLOTTO, Heloísa Liberalli. Arquivos permanentes: tratamento documental. 3. ed. Rio de Janeiro: FGV, 2006.

BELLOTTO, Heloísa Liberalli. As espécies documentais. In: Como fazer análise diplomática e análise tipológica de documento de arquivo. São Paulo: Arquivo do Estado, Imprensa Oficial, 2002. p. 45-90. (Projeto Como Fazer, v. 8)

BIDERMAN, Maria Tereza Camargo. Os dicionários na contemporaneidade: arquitetura, métodos e técnicas. In: OLIVEIRA, Ana Maria Pinto Pires de; ISQUERDO, Aparecida Negri (Orgs.) As ciências do léxico: lexicologia, lexicografia, terminologia. Campo Grande: EDUFMS, 2001. p. $131-144$.

BLUTEAU, Raphael. Vocabulario portuguez \& latino: aulico, anatomico, architectonicco.... Coimbra: Collegio das Artes da Companhia de Jesu, 1712-1728. 8 v. Disponível em: $<$ http://www.brasiliana.usp.br/dicionario/edição/1>.

CAMBRAIA, César Nardelli. Introdução à crítica textual. São Paulo: Martins Fontes, 2005.

CHARTIER, Roger. Escutar os mortos com os olhos. In: A mão do autor e a mente do editor. Tradução George Schlesinger. São Paulo: Editora UNESP, 2010. p. 7-30.

COELHO, Braz José. Dicionários: estrutura e tipologia. In: COELHO, Braz José. Linguagem lexicologia e ensino de português. Catalão: Kaio Gráfica e Editora Ltda, 2008. p. 13-41.

DANTAS, Mônica. Revoltas, motins, revoluções: homens livres pobres e libertos no Brasil do século XIX. São Paulo: Alameda, 2011.

DIAS, Madalena Marques; BIVAR, Vanessa dos Santos Bodstein. Paleografia para o período colonial. In: SAMARA, Eni de Mesquita. (Org.) Paleografia e fontes do período colonial brasileiro. São Paulo: Humanitas/FFLCH/USP, 1986. p. 11 - 38. (Estudos CEDHAL/ Centro de Estudos de Demografia Histórica da América Latina, nova série, n. 11)

FACHIN, Phablo Roberto Marchis. Estudo paleográfico e edição semidiplomática de manuscritos do Conselho Ultramarino (1705-1719). Dissertação (Mestrado em Filologia e Linguística Portuguesa). Faculdade de Filosofia, Letras e Ciências Humanas, Universidade de São Paulo, São Paulo, 2006. 
GONÇALVES, Eliana Correia Brandão. Diálogos entre Crítica Filológica e Linguística Histórica: construindo trilhas para o estudo linguístico de textos históricos. In: ATAÍDE, Cleber et al. (Orgs.) Estudos linguísticos e literários [recurso eletrônico]: caminhos e tendências. 1 ed. São Paulo: Pá de Palavra, 2019, v. 1. p. 11-20.

GONÇALVES, Eliana Correia Brandão. Leitura crítico-filológica de Resolução de 1822: revoltas, vigilância, violência e punição na Bahia do século XIX. Revista Filologia e Linguística Portuguesa, São Paulo, v. 20, n. 2, p. 153-174, ago./dez. 2018. http://dx.doi.org/10.11606/issn.2176-9419.v20i2p153-174.

GONÇALVES, Eliana Correia Brandão. Léxico e história: lutas e contextos de violência em documentos da Capitania da Bahia. Revista da ABRALIN, v.16, n.2, p. 191-218, abr. 2017. Disponível em: <https://revistas.ufpr.br/abralin/article/view/52006>. Acesso em: 14 ago. 2019. Doi: http://dx.doi.org/10.5380/rabl.v16i2.52006.

HAENSCH, Günther. Tipología de las obras lexicográficas. In: HAENSCH, Günther; WOLF, Lothar; ETTINGER, Stefan; WERNER, Reinhold. (Eds.). La Lexicografía: de la Lingüística Teórica a la Lexicografía Práctica. Madrid: Editorial Gredos, 1982. p. 95-187.

MAIA, Clarinda. Linguística Histórica e Filologia. In: LOBO, Tânia et al. ROSAE: linguística histórica, história das línguas e outras histórias. Organizadoras: Salvador: EDUFBA, 2012. p. $533-542$.

MARQUILHAS, Rita. Filologia oitocentista e Crítica Textual. In: ALVES, Fernanda Mota et al. (Orgs.) Filologia, memória e esquecimento. Act. 20, Lisboa: Húmus, 2010. p. 355 - 367.

MATTOS E SILVA, Rosa Virgínia. Caminhos da linguística histórica: ouvir o inaudível. São Paulo: Parábola, 2008.

MORAES SILVA, Antonio de. Diccionario da lingua portugueza. 2 ed. Lisboa: Typographia Lacerdina, 1813. Disponível em: 〈http://www.brasiliana.usp.br/en/dicionario/edição/2>.

MURAKAWA, Clotilde de Almeida Azevedo. Dicionario Histórico do Português do Brasil: testemunho lexical da língua portuguesa no Brasil Colônia. Debate Terminológico, 14, p. 75$88,2015$.

MURAKAWA, Clotilde de Almeida Azevedo. Tradição lexicográffica portuguesa: Bluteau, Morais e Vieira. In: OLIVEIRA, Ana Maria Pinto Pires de; ISQUERDO, Aparecida Negri (Orgs.) As ciências do léxico: lexicologia, lexicografia, terminologia. 2 ed. Campo Grande: EDUFMS, 2001. p. 151-157.

MURAKAWA, Clotilde; GONÇALVES, Maria Filomena. The corpus of the Dicionário Histórico do Português do Brasil (DHPB). In: SILVESTRE, João Paulo; VILLALVA, Alina (Eds.). Planning non-existent dictionaries. Lisboa/Aveiro: Centro de Linguística da Universidade de Lisboa/Universidade de Aveiro, 2015. p. 19-41. (Dicionarística portuguesa; 4)

NUNES, Antonietta d'Aguiar. Conhecendo a história da Bahia da pré-história a 1815. Salvador: Quarteto, 2013. 
PONS RODRÍGUEZ, Lola. Introducción: la historia de la lengua y la história de las transmisiones textuales. In: PONS RODRÍGUEZ, Lola. (Ed.) Historia de la lengua y crítica textual. Madrid/ Frankfurt: Iberoamericana/ Vervuert, 2006. p. 9 - 17.

PORTO DAPENA, José-Álvaro. Manual de técnica lexicográfica. Madrid: Arco/Libros, 2002.

REIS, João José. Quilombos e revoltas escravas no Brasil. Revista USP, São Paulo, 28, p. 14-39, dezembo/fevereiro de 1995-1996.

REIS, João José. Recôncavo rebelde: revoltas de escravos nos engenhos bahianos. Afroásia, Salvador, 15, p. $100-126,1992$.

REY-DEBOVE, Josette. Lexique et dictionnaire. In: POTTIER, Bernard. (Org.) Le langage. Paris: Retz, CEPL, 1973. p. 82-109.

SECO, Manuel. Las palabras en el tiempo: los diccionarios históricos. In: Estudios de lexicografía española. 2 ed. aum. Madrid: Editorial Gredos, 2003. p. 109 - 156. (Biblioteca Románica Hispánica)

TAVARES, Luís Henrique Dias. História da Bahia. 10. ed. São Paulo: UNESP; Salvador: EDUFBA, 2001.

VIEIRA, Fr. Domingos. Grande diccionario portuguez ou thesouro da língua portuguesa. Porto: Ernesto Chardron e Bartholomeu H. de Moraes. 1871-1874. 5 v. (Publ. feita sobre o manuscrito original, inteiramente revisto e consideravelmente aumentado). 